\title{
TEORIA DA PROTEÇÃO INTEGRAL: PRESSUPOSTO PARA COMPREENSÃO DO DIREITO DA CRIANÇA E DO ADOLESCENTE
}

André Viana Custódio*

\section{RESUMO}

O artigo analisa a teoria da proteção integral e o Direito da Criança e do Adolescente. Descreve os princípios da teoria da proteção integral, analisa a doutrina da situação irregular e estuda os fundamentos jurídicos para concretização dos direitos da criança e do adolescente no Brasil contemporâneo. Proteção.

Palavras-chave: Adolescente. Criança. Direitos. Proteção. Teoria.

\section{CONSIDERAÇÕES INICIAIS}

A teoria da proteção integral estabeleceu-se como necessário pressuposto para a compreensão do Direito da Criança e do Adolescente no Brasil contemporâneo. As transformações estruturais no universo político consolidadas no encerrar do século XX contrapuseram duas doutrinas de traço forte, denominadas da situação irregular e da proteção integral. Foi a partir desse momento que a teoria da proteção integral tornou-se referencial paradigmático para a formação de um substrato teórico constitutivo do Direito da Criança e do Adolescente no Brasil.

Por isso, a compreensão do novo Direito da Criança e do Adolescente exigiu uma teoria jurídica própria resultante do conflito de valores produzidos por doutrinas distintas, mas que acabaram por alcançar um status teórico substantivo orientador da compreensão de valores, princípios e regras próprias.

Talvez, a maior parte das incongruências relativas ao tema infância e juventude no Brasil resulte num descompasso, compreensível historicamente, embora indiscutivelmente injusto, que denota uma transição entre compreensões distintas sobre um mesmo tema. Trata-se nada mais que uma resistência, obscurecida por caracteres e práticas de caráter tecnicista, que insistem, pela tradição ou pela dificuldade de compreensão do novo paradigma, em tentar realizar uma leitura do Direito da Criança e do Adolescente com as lentes epistêmicas da antiga doutrina da situação irregular.

De todo modo, a constituição do Direito da Criança e do Adolescente no Brasil alcançou uma capacidade de afirmação teórica incontestável, desestruturando todas as demais concepções, que historicamente legitimavam seu anverso, ou seja, o Direito do Menor. Uma aproximação da estrutura 
interna desses sistemas diversos pode dar melhores pistas sobre estas mudanças, mas de todas elas sem dúvida ficam evidenciadas as radicais transformações no campo dos princípios, regras e conceitos inerentes às duas doutrinas.

É preciso advertir que a afirmação do Direito da Criança e do Adolescente no Brasil não decorre de um modo de acumulação epistemológica, mas antes de tudo, representa ruptura radical com a própria compreensão histórica relativa ao tema. Surge com força capaz de varrer todos os pressupostos teóricos da doutrina da situação irregular, primeiro contestando sua própria validade científica, e depois formulando um conjunto de conceitos operacionais, regras, sistemas integrados e articulados em rede que tornaram absolutamente incompatível a congruência de um modelo com o outro.

Sobre esses processos transformadores, Kuhn ${ }^{1}$ esclarece que no desenvolvimento de uma ciência, quando

\begin{abstract}
[...] um indivíduo ou um grupo produz uma síntese capaz de atrair a maioria dos praticantes de ciência da geração seguinte, as escolas mais antigas começam a desaparecer gradualmente. Seu desaparecimento é em parte causado pela conversão de seus adeptos ao novo paradigma. Mas sempre existem alguns que se aferram a uma ou mais concepções mais antigas; são simplesmente excluídos da profissão e seus trabalhos são ignorados. O novo paradigma implica uma definição nova e mais rígida do campo de estudos. Aqueles que não desejam ou não são capazes de acomodar seu trabalho a ele têm que proceder isoladamente ou unir-se a algum grupo.
\end{abstract}

Sem dúvida, a teoria da proteção integral consolidou-se como verdadeiro paradigma na compreensão da infância e adolescência no Brasil. Daí decorre tentativa em regra sem sucesso, de reacionar o velho modelo por meio de mudanças pontuais na legislação infanto-juvenil, mas que não subsistem por muito tempo, pois o que sustenta o Direito da Criança e do Adolescente é estruturalmente complexo para ceder às mudanças pontuais incompatíveis com a lógica sistemática desse novo campo do conhecimento jurídico da infância.

Embora quase todos os pesquisadores da área façam o registro da transição do Direito do Menor (Doutrina da Situação Irregular) para o Direito da Criança e do Adolescente (Doutrina da Proteção Integral); poucos se dedicaram à compreensão das complexas e profundas mudanças decorrentes dessa ruptura histórica. Talvez, a própria proximidade histórica dessas mudanças contribua para a dificuldade em se afirmar a amplitude, profundidade e complexidade dessas transformações.

\title{
2 A DOUTRINA JURÍDICA DA SITUAÇÃO IRREGULAR
}

A doutrina jurídica da situação irregular tem raízes em concepções que remontam ao início do século XIX. Foi articulada no ambiente jurídico com a edição de um Código de Menores em $1927^{2}$ que organizou as leis então 
existentes sobre assistência e proteção aos menores e, posteriormente, rearticulada com uma nova edição com a aprovação da Lei n. 6.697, de 10 de outubro de 1979, que instituiu um outro Código de Menores ${ }^{3}$. Este código adotaria explicitamente a doutrina da situação irregular.

Nesta época, o jurista Ubaldino Calvento já reconhecia a existência de três escolas no I Congresso lbero-Americano de Juízes de Menores realizado na Nicarágua, definindo-as como:

\begin{abstract}
1a - Doutrina da proteção integral - partindo dos direitos das crianças, reconhecidos pela ONU, a lei asseguraria a satisfação de todas as necessidades das pessoas de menor idade, nos seus aspectos gerais, incluindo-se os pertinentes à saúde, educação, recreação, profissionalização, etc.

2 - Doutrina do Direito Penal do Menor - somente a partir do momento em que o menor pratique ato de delinqüência interessa ao direito.

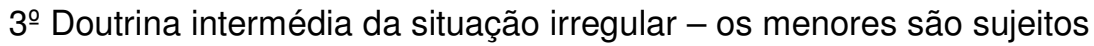
de direito quando se encontrarem em estado de patologia social, definida legalmente. É a doutrina brasileira. ${ }^{4}$
\end{abstract}

Embora apresentada como novidade e adotada pelos reconhecidos juristas como "a doutrina brasileira", é preciso destacar que, a concepção de situação irregular já esgotava nesta época suas potencialidades históricas pela própria incapacidade de resolver os problemas que selecionava como relevantes. Além disso, convivia com margem de outros problemas não esperados, nem previstos e, em regra, desprezados como significativos o suficiente para serem estudados e concretizados.

Havia nessa concepção uma resistência discursiva específica, que produziu uma visão estigmatizada de infância e juridicamente era aprisionada pelos conceitos positivistas clássicos da menoridade. A objetivação jurídica do conceito de "menor" atribuía toda uma gama de políticas de tratamento à menoridade legitimando o reforço de políticas de controle social, vigilância e repressão. Leite ${ }^{5}$ reconhece que

\begin{abstract}
A partir de uma análise sistemática do Código de Menores de 1979 e das circunstâncias expostas, podem-se extrair as seguintes conclusões quanto à atuação do Poder Estatal sobre a infância e a juventude sob a incidência da Doutrina da Situação Irregular: (i) uma vez constatada a "situação irregular", o "menor" passava a ser objeto de tutela do Estado; e (ii) basicamente, toda e qualquer criança ou adolescente pobre era considerado "menor em situação irregular", legitimando-se a intervenção do Estado, através da ação direta do Juiz de Menores e da inclusão do "menor" no sistema de assistência adotado pela Política Nacional do Bem-Estar do Menor.
\end{abstract}

O papel do Estado estava alinhado à perspectiva de um modelo autoritário que supostamente o sustentava, onde a atuação estava direcionada para a contenção pela via da violação e restrição dos direitos humanos; tendo por conseqüência a (re)produção das condições planificadas de exclusão social, econômica e política, assentada em critérios individuais que acentuavam as práticas de discriminação racial e de gênero, segundo o qual o marco referencial construía uma imagem de infância por aquilo que ela não 
tinha e não era. A teoria jurídica das incapacidades foi neste ambiente o instrumento operacional necessário à afirmação e manutenção dessas condições, reduzindo o ser humano à condição de destituído, reafirmando uma concepção negativa, redutora, embasada no adultocentrismo. ${ }^{6}$

Quando se procura relações entre a doutrina da situação irregular e a ideologia da segurança nacional torna-se evidente a idéia de centralização como o referencial para o modelo de gestão de políticas públicas predominante, que sem dúvida, posteriormente levaria a desestrutura completa ao final da ditadura militar, pois à qualidade da atuação estatal restringia-se, cada vez mais, pela forma autoritária e não-participativa imposta à administração pública, incompatível com um país que almejava a participação popular. Para manter tal sistema organizavam-se práticas de controle centralizado e repressivo sobre as entidades associativas e forte pressão sobre os movimentos sociais.

De outro modo, os poderes legislativo, executivo e judiciário mantinhamse regularmente omissos manifestando-se apenas quando as crianças assumiam a condição de objeto de interesse "jurídico", seja pela prática de infrações, seja pela própria condição de exclusão social que as colocava em evidência. Aí, era o momento de configurar a irregularidade, que nunca era das instituições, mas sempre recaía sobre a criança, pela própria previsão ordenada no sistema jurídico ou pela condição de fragilidade que a submetia as imposições adultas produzindo o paradoxo da reprodução da exclusão integral pela via da inclusão na condição de objeto de repressão.

A teoria jurídica do direito do menor desempenhava papel especial na re-significação da realidade, pois dispunha de um aparato capaz de transformar o menino e a menino pobre em "menor em situação de risco" e, portanto, destinatário da responsabilização individual pela sua própria condição de irregularidade. Era a construção de um mundo paralelo, onde a irregularidade era imaginada com base em preconceitos e estereótipos e depois restava aos agentes do Estado enquadrar o público perfeito à caracterização da barbárie.

Para que isso fosse possível era preciso convencê-los que eram concretamente os responsáveis pela sua própria condição, numa tentativa de imunizar às críticas ao perverso sistema econômico estabelecido, como se não houvesse correlação alguma com as condições econômicas estruturais e a desigualdade social. Bastava que a vítima subjetivasse a própria culpa. Essa lógica sistemática foi especialmente intensa num país em que o tema era "o problema do menor".

A própria concepção de problema do menor tem origem no universo dos juristas decorrente da organização, em quase todos os anos da década de 1950 e nos anos seguintes, pelos Tribunais de Justiça dos Estados de São Paulo e Rio de Janeiro das "Semanas de Estudos dos Problemas dos Menores".

$\mathrm{Na}$ medida em que a idéia de situação irregular deslocava para o campo de atenção do sistema de justiça problemas complexos de ordem econômica e social, o Poder Judiciário aprimorava seu campo de atuação na gestão direta 
das ações sociais produzindo um tipo característico de magistrado, um misto de gestor assistencialista com agente de repressão policial; que em regra oferecia como contrapartida a prática dominante e freqüente da institucionalização em massa mediante a inserção nos esquemas técnicos da Política Nacional do Bem-Estar do Menor.

$V_{\text {Veronese }}^{7}$ explica que "A partir do momento que o problema da infância adquire status de problema social, sobre ele recaem os preceitos da ideologia da segurança nacional. A PNBEM - Política Nacional do Bem-Estar do Menor tem assim toda a sua estrutura autoritária resguardada pela Escola Superior de Guerra [...]." Sobre este aspecto Lima ${ }^{8}$, acrescenta:

\begin{abstract}
[...] o modelo jurídico menorista, representado pelo binômio 'Código de Menores/Doutrina Jurídica da Situação Irregular', não era apenas uma forma de controle individualizado dos menores irregulares. Era também uma forma de se projetar o controle social numa perspectiva de classe. A partir do padrão de organização da família burguesa, como 'célula mater da nação brasileira', impunha-se traçar o destino, estabelecer os valores morais, o perfil das relações inter-familiares, a lógica dos comportamentos, a serem adotados pelos setores populares. Este era o caminho disponível à sua redenção das famílias pobres, sob pena de serem contra elas movidas as engrenagens do Sistema legal menorista.
\end{abstract}

Contudo, já a partir do início da década de 1980 foi especialmente claro a contraposição das duas principais doutrinas (da situação irregular e da proteção integral) que disputavam hegemonia teórica sobre a titularidade de esquemas conceituais mais adequados às necessidades brasileiras, ou seja, o edifício teórico da doutrina brasileira da situação irregular começava a ruir.

\title{
3 A TEORIA JURÍDICA DA PROTEÇÃO INTEGRAL
}

$\mathrm{Na}$ década de 1980, surge um ambiente que almejava a democratização, onde os movimentos sociais assumiam o papel de protagonistas na produção de alternativas ao modelo imposto. O imperativo discursivo produzido pelo Estado autoritário recebia a contribuição crítica do espaço público e, portanto, político de reflexão sobre as práticas históricas instituídas sobre a infância.

Inaugura-se aí uma fase enriquecedora, na qual a vitória estava anunciada, pois o enfrentamento entre a doutrina jurídica da situação irregular perdia adeptos na mesma proporção em que doutrina da proteção integral ganhavam novos aliados. Finalmente, a nessa década conviveria uma utopia mobilizadora para a construção de uma sociedade aonde todos poderiam gozar de direitos humanos reconhecidos como fundamentais na nova Constituição que se elaborava. Estava traçada a oportunidade histórica para sepultar 0 menorismo no Brasil.

No entanto, a contraposição evidente entre a doutrina da situação irregular e a doutrina da proteção integral trouxe resultados para além do que se esperava, pois o marco referencial dessas transformações não se restringiu 
exatamente apenas no enfrentamento político entre as duas doutrinas. Trouxe resultados positivos para além do desejado.

Esse processo de transição contou com a colaboração indispensável dos movimentos sociais em defesa dos direitos da infância, que juntamente à reflexão produzida em diversos campos do conhecimento, inclusive àqueles considerados jurídicos, proporcionou a cristalização do Direito da Criança e do Adolescente com uma perspectiva diferenciada anunciando reflexos radicalmente transformadores na realidade concreta. Por isso, a teoria da proteção integral deixa de se constituir apenas como obra de juristas especializados ou como uma declaração de princípios propostos pela Organização das Nações Unidas uma vez que incorporou na sua essência a rica contribuição da sociedade civil brasileira.

Adiciona-se a esta realidade que a teoria da proteção integral incorporou-se antecipadamente no ordenamento jurídico brasileiro, até mesmo antes da própria edição da Convenção Internacional dos Direitos da Criança. Como bem registra Ramidoff',

\begin{abstract}
Em que pese o fato de se ter politicamente adotado na Constituição da República de 1988 a doutrina da proteção integral antes mesmo da oficialização do conjunto de instrumentos legislativos internacionais - e dentre eles, em particular, a Convenção Internacional dos Direitos Humanos da Criança que é do ano de 1989 - percebe-se que intenso movimento popular brasileiro já havia ensejado (re)alinhamento democrático interno com as diversas dimensões humanitárias dos direitos mais comezinhos àquelas pessoas que se encontrassem na condição peculiar de desenvolvimento da personalidade.
\end{abstract}

A promulgação da Constituição da República Federativa do Brasil ${ }^{10}$, em 05 de outubro de 1988, configurou uma opção política e jurídica que resultou na concretização do novo direito embasado na concepção de democracia. Segundo Costa \& Hermany ${ }^{11}$

[...] foi possível a incorporação dos novos ideais culturais surgidos na sociedade, implementando, ao menos formalmente, a democracia participativa. A proposta é de que a descentralização e democratização caminhem conjuntamente, a fim de garantir a formulação de políticas públicas eficazes, que respondam satisfatoriamente aos anseios da população e que sejam capazes de prevenir e combater a tão propalada exclusão social [...].

A Constituição da República Federativa do Brasil e suas respectivas garantias democráticas constituíram a base fundamental do Direito da Criança e do Adolescente interrelacionado os princípios e diretrizes da teoria da proteção integral, que por conseqüência provocou um reordenamento jurídico, político e institucional sobre todos planos, programas, projetos ações e atitudes por parte do Estado, em estreita colaboração com a sociedade civil, nos quais os reflexos se (re)produzem sobre o contexto sócio-histórico brasileiro.

A constituição de uma base epistemológica consistente possibilitou a doutrina da proteção integral reunir tal conjunto de valores, conceitos, regras, 
articulação de sistemas e legitimidade junto à comunidade científica que a elevou a um outro nível de base e fundamentos teóricos, recebendo, de modo mais imediato, a representação pela idéia de Teoria da Proteção Integral. Segundo Ramidoff ${ }^{12}$ :

\begin{abstract}
A pretensão de integração sistemática da teoria e da pragmática pertinentes ao direito da criança e do adolescente certamente se constitui num dos objetivos primordiais a serem perseguidos pela teoria jurídica infanto-juvenil. Até porque uma das principais funções instrumentais oferecidas pela proposta da formatação daquela teoria jurídico-protetiva é precisamente oferecer procedimentos e medidas distintas por suas necessidades e especificidades no tratamento de novas emergências humanas e sociais, procurando-se, desta maneira, estabelecer outras estratégias e metodologias para proteção dos valores sociais democraticamente estabelecidos - como, por exemplo, direitos e garantias individuais fundamentais - pertinentes à infância e à juventude.
\end{abstract}

A formulação da Teoria da Proteção Integral não seria objeto de maior interesse, ou apenas mais uma teoria abstrata, se não estivesse radicalmente localizada como o elemento substantivo essencial para a compreensão do Direito da Criança e do Adolescente. Contudo, é preciso reconhecer certos limites evidentes, pois justamente quando se coloca em análise a base teórica formulada sobre o Direito da Criança e do Adolescente, dos quais os manuais jurídicos são as expressões mais transparentes, surgem incongruências interpretativas absurdas.

Sem maior risco de erro, é possível observar que, em regra, os manuais, e grande parte dos textos acadêmicos especializados, não apresentam coerência interna e correlação que permitam distinguir as duas doutrinas. $\mathrm{E}$, menos ainda, há evidência nos manuais que exista uma teoria específica que embasa do Direito da Criança e do Adolescente, pois nessa tradição ainda é radicalmente desconsiderada, e na maior parte substituídas por convicções individuais sem qualquer tipo de correspondência com a realidade concreta dos esquemas político-jurídicos em ação. Quando se aproxima de temas específicos do Direito da Criança e do Adolescente, tais como os temas da violência e do ato infracional, esses distorções são ainda mais visíveis.

Por isso, tornou-se freqüente entre os reconhecidos pesquisadores sobre o tema manterem advertências indispensáveis sobre os processos de mudança. Veronese \& Rodrigues ${ }^{13}$, por exemplo, destacam essa necessidade ao relembrar:

\footnotetext{
O cuidado dos que trabalham com o Direito da Criança e do Adolescente deve se dar também no plano da linguagem.

Utiliza-se indiscriminadamente a expressão 'adolescente infrator' ou o que é ainda pior: 'menor infrator', esta última preza a concepção do menorismo (Códigos de Menores de 1927 e 1979), segundo a qual reduzia-se a objeto a nossa infância.
}

Nesse contexto, surge como problema o reconhecimento do Direito da Criança e do Adolescente como ramo jurídico que requer uma compreensão de sua base teórica essencial denominada de Teoria da Proteção Integral e, que o delineamento de seus princípios regras pode ser especialmente útil para 
afastar confusões, principalmente àquelas tendentes a estabelecer relações entre as duas doutrinas, aqui entendidas como incompatíveis; ou ainda àquelas tendentes a demonstração que uma é decorrente da acumulação histórica de experiências da doutrina anterior. "É por isso que uma nova teoria, por mais particular que seja seu âmbito de aplicação, nunca ou quase nunca é um mero incremento ao que já é conhecido."14

Há possibilidades concretas para se demonstrar que as forças que constituíram a Teoria da Proteção Integral resultaram em grande parte da contraposição da doutrina da situação irregular e da doutrina da proteção integral produzindo algo diferente, com magnitude capaz de consolidar elementos com capacidade suficiente para afirmar o Direito da Criança e do Adolescente como um campo jurídico aberto de possibilidades, mas seguro quanto às suas diretrizes, princípios, regras e valores.

Essa inquietação, freqüente entre os pesquisadores da área, quando confrontados com certo tipo de produção acadêmica, pouco rigorosa, mas resiliente, que constrói explicações lógicas articulando conceitos e teorias (a)históricas e sem relação, sem dúvida, incompatíveis e que apresentam como resultado a incoerência do próprio sistema, num esforço teórico que não pode resultar em algo distinto, pois em regra o que está em conflito são os próprios princípios e conceitos radicalmente distintos e que não podem ser observados como se fizesse parte de uma mesma realidade.

Neste aspecto, é reveladora a afirmação, freqüente em muitos textos acadêmicos, que declara não encontrar maior distinção entre os termos menor $x$ criança e adolescente, quando na realidade a distinção entre elementos tão básicos revela a incompreensão da complexidade distintiva entre percepções radicalmente diversas, ou seja, desconsidera-se o essencial, o reconhecimento da transição paradigmática do Direito do Menor para o Direito da Criança e do Adolescente.

É claro, que a constituição de uma nova teoria, mesmo reconhecida como legítima pela comunidade científica, nem sempre poderá responder imediatamente a todos os problemas que lhe são propostos; pois é necessário o tempo para sua realização, e mesmo assim, inúmeros outros problemas não serão resolvidos, seja porque não faz parte do conjunto estrutural básico dessa teoria ou ainda por não estar no foco de interesse principal dos cientistas.

É preciso lembrar que uma ruptura paradigmática traz consigo a proposição de outros problemas antes desconhecidos ou desconsiderados, mas ao mesmo tempo abandona problemas antes selecionados como relevantes. Isso pode observado com clareza na comparação entre os problemas teóricos propostos pelas duas doutrinas e, essencialmente pela substituição dos objetos, métodos e técnicas de estudos. Sob este aspecto o Direito da Criança e do Adolescente apresenta poucas relações com o modelo do Direito do Menor, pois estão constituídos por valores, princípios, regras, métodos e problemas científicos radicalmente diferenciados, daí se poder afirmar que a contraposição dialética das duas doutrinas produziu uma verdadeira teoria, capaz de ser aferida por meio de métodos, técnicas e procedimentos científicos. 


\begin{abstract}
A transição de um paradigma em crise para um novo, do qual pode surgir uma nova tradição de ciência normal, está longe de ser um processo cumulativo obtido através de uma articulação do velho paradigma. É antes uma reconstrução da área de estudos a partir de novos princípios, reconstrução que altera algumas das generalizações teóricas mais elementares do paradigma, bem como muitos de seus métodos e aplicações. ${ }^{15}$
\end{abstract}

Sob o ponto de vista normativo, há uma distinção muito lúcida nessas rupturas, e quando observado com a devida distinção e método torna-se viável a verificação de todos os elementos necessários para afirmação teoria da proteção integral. Por outro lado, ainda há pontos obscuros, que ainda não são passíveis de resolução, tais como as distinções essenciais entre a "doutrina" e a "teoria" da proteção integral. No entanto, há indícios suficientes para se confiar numa superação de uma mera concepção doutrinária, baseada em dogmas e pressupostos simplesmente abstratos.

Gradativamente a dimensão teórica da proteção integral vem ganhando espaços privilegiados, tanto nos trabalhos acadêmicos mais recentes vinculando-a a uma concepção de práxis política, quanto na própria problematização de seus pressupostos realizados nos meios acadêmicos e, inclusive, em ambientes radicalmente democráticos de discussão e reflexão da teoria, bem como, de suas conseqüências na realidade social, tais como as Conferências de Direitos da Criança e do Adolescente, nos Fóruns Temáticos, nas Audiências Públicas e nos próprios Conselhos de Direitos da Criança e do Adolescente.

Para a elaboração de uma teoria do Direito da Criança e do Adolescente $\operatorname{Lima}^{16}$ propõe uma abordagem principiológica reconhecendo um caráter duplamente sistemático, ou seja, como um sistema de princípios e regras e de direitos fundamentais, por isso diz o autor:

\begin{abstract}
Podemos então falar do Direito da Criança e do Adolescente como um novo modelo jurídico, isto é, um novo ordenamento de direito positivo, uma nova teoria jurídica, uma nova prática social (da sociedade civil) e institucional (do poder público) do Direito. O que importa, neste caso, é perceber que desde a criação legislativa, passando pela produção do saber jurídico, até a interpretação e aplicação a situações concretas, este Direito impõe-nos o inarredável compromisso ético, jurídico e político com a concretização da cidadania infanto-juvenil.
\end{abstract}

A idéia central da proteção integral à criança e ao adolescente foi capaz de articular uma teoria própria em determinado momento histórico, porque conseguiu ao mesmo tempo conjugar necessidades sociais prementes aos elementos complexos que envolveram mudança de valores, princípios, regras e neste contexto conviver com a perspectiva emancipadora do reconhecimento dos direitos fundamentais à criança e ao adolescente.

Nesse sentido, Ramidoff ${ }^{17}$ propõe ao Direito da Criança e do Adolescente uma propedêutica jurídica-protetiva transdisciplinar:

O desenvolvimento da teoria jurídico-protetiva reclama, pois, uma propedêutica de viés transdisciplinar que lhe seja específica e 
particularmente própria, mas, isto não significa isolamento, e, sim, possibilidade teórica e pragmática de autonomia e eliminação falsificacionista de tudo aquilo que ameace ou viole as condições mínimas de existência digna das pessoas que se encontram na condição peculiar de desenvolvimento da personalidade: crianças e adolescentes.

Como conseqüência, a teoria da proteção integral ousou estender seu campo de atuação para a articulação de estratégias de transformação representadas pela construção do sistema de garantias de direitos da criança e do adolescente e toda uma inovadora rede institucional, que lhe dá sustentação e legitimidade política fundada em um modo de organização em redes descentralizadas.

A construção do Direito da Criança e do Adolescente proporcionou significativo processo de reordenamento institucional, com a desjudicialização das práticas de caráter administrativo; com mudanças de conteúdo, método e gestão, bem como, a integração dos princípios constitucionais da descentralização político-administrativa e da democratização na efetivação dos direitos fundamentais da criança e do adolescente que, a partir daí, têm reconhecido seu status de sujeito de direitos, garantindo o irrestrito, amplo e privilegiado acesso à Justiça. ${ }^{18}$

De todo modo, a teoria da proteção integral não apresenta rigidez às mudanças ou estabelece-se como normativamente estática. Mas o modo pelo qual foi produzida, transformando toda uma cultura em torno de uma visão sobre a infância no Brasil, ofereceu condições especiais de resiliência suficiente para resistir às agressões mais significativas sobre seus problemas de interesse central. Daí a dificuldades dos reformadores em compreender 0 quão limitado pode ser qualquer esforço de alteração pontual de seu sistema.

Enquanto houver espaço para a construção de esquemas que respondam à formulação dos problemas teóricos básicos, a Teoria da Proteção Integral tende a se manter consistente. Até porque sua própria característica de nova teoria a mantém num espaço obscuro suficiente para confundir os mais afoitos. Não há na literatura científica sobre o Direito da Criança e do Adolescente qualquer tipo de indício consistente que possa ameaçar a domínio hegemônico da teoria ou a sua superação em médio prazo. As únicas tentativas, mais visíveis, provêm de um campo superado, frágil e tendente à extinção, que reúne saudosos atores da superada doutrina da situação irregular.

Se a Teoria da Proteção Integral ocupa esse lugar com um ponto de convergência, torna-se, portanto, imprescindível compreender seus reais limites, conteúdos e a própria dinâmica no qual está constituída, para que ao menos, torne-se operativa o suficiente para responder aos problemas complexos da concretização dos Direitos da Criança e do Adolescente.

O Direito da Criança e do Adolescente encontra fundamento jurídico essencial na Convenção Internacional sobre os Direitos da Criança, na Constituição da República Federativa do Brasil, no Estatuto da Criança e do Adolescente e nas convenções internacionais de proteção aos direitos 
humanos. No entanto, para sua adequada compreensão, é fundamental percorrer seus princípios fundamentais. Para Bruñol ${ }^{19}$ :

\footnotetext{
Os princípios, no marco de um sistema jurídico baseado no reconhecimento de direitos, pode-se dizer que são direitos que permitem exercer outros direitos e resolver conflitos entre direitos igualmente reconhecidos.

Entendendo deste modo a idéia de 'princípios', a teoria supõe que eles se impõem às autoridades, isto é, são obrigatórios especialmente para as autoridades públicas e vão dirigidos precisamente para (ou contra) eles.
}

Lima $^{20}$ analisou o conjunto de princípios do Direito da Criança e do Adolescente, merecendo destaque para 0 estudo sobre os princípios estruturantes e concretizantes. O autor inclui entre os princípios estruturantes a vinculação à teoria da proteção integral, a universalização, o caráter jurídicogarantista e o interesse superior da criança.

Como princípios concretizantes, Lima $^{21}$ estabelece a prioridade absoluta, a humanização no atendimento, a ênfase nas políticas sociais públicas, a descentralização político-administrativa, a desjurisdicionalização, a participação popular, a interpretação teleológica e axiológica, a despoliciação, a proporcionalidade, a autonomia financeira e a integração operacional dos órgãos do poder público responsáveis pela aplicação do Direito da Criança e do Adolescente.

O mais evidente princípio do Direito da Criança e do Adolescente é aquele de vinculação à Teoria da Proteção Integral, previsto no art. 227, da Constituição Federal e também no Estatuto da Criança e do Adolescente, nos artigos $1^{\circ}$ e $3^{\circ}$.

A Teoria da Proteção Integral sustenta Veronese ${ }^{22}$, desempenha papel estruturante no sistema na medida em que o reconhece sob a ótica da integralidade, ou seja, o reconhecimento de todos os direitos fundamentais inerentes à pessoa humana e, ainda, direitos especiais decorrentes da condição peculiar de pessoa em desenvolvimento, que se articulam, produzem e reproduzem de forma recíproca.

Os direitos especiais de proteção também estão previstos no art. 227, da Constituição Federal e regulamentados no Estatuto da Criança e do Adolescente, no art. 5o, prevendo que: "Nenhuma criança ou adolescente será objeto de qualquer forma de negligência, discriminação, exploração, violência, crueldade e opressão, punido na forma da lei qualquer atentado, por ação ou omissão, aos seus direitos fundamentais".

O reconhecimento dos direitos fundamentais à criança e ao adolescente trouxe consigo o princípio da universalização, segundo o qual os direitos do catálogo são susceptíveis de reivindicação e efetivação para todas as crianças e adolescentes. No entanto, a universalização dos direitos sociais como àqueles que dependem de uma prestação positiva por parte do Estado, também exige uma postura pró-ativa dos beneficiários nos processos de reivindicação e construção de políticas públicas. É nesse sentido que o Direito da Criança e do Adolescente encontra seu caráter jurídico-garantista, segundo 
o qual a família, a sociedade e o Estado têm o dever de assegurar a efetivação dos direitos fundamentais, ou seja, transformá-los em realidade.

O Direito da Criança e do Adolescente emerge como um sistema orientado pelo princípio do interesse superior da criança, previsto no art. $3^{\circ}$, 1 , da Convenção Internacional sobre os Direitos da Criança, determinando que "Todas as ações relativas às crianças, levadas a efeito por instituições públicas ou privadas de bem estar social, tribunais, autoridades administrativas ou órgãos legislativos, devem considerar, primordialmente o maior interesse da criança." E um princípio decorrente do reconhecimento da condição peculiar da criança como pessoa em processo de desenvolvimento.

A origem do princípio do interesse superior da criança está localizada no modelo de sociedade desigual produzido pelo sistema capitalista, potencialmente gerador de conflitos de interesses. Segundo, Paula ${ }^{23}$ :

\begin{abstract}
Em conseqüência das necessidades humanas brota a noção de interesse, concebido como razão entre sujeito e o objeto. Objeto do interesse do homem é um bem, podendo ser, 'grosso modo', material ou imaterial. Como os bens jurídicos são finitos, inexistindo em quantidade ou qualidade para satisfazer a todos os interesses humanos, inexoravelmente advêm conflitos. Quando um mesmo homem tem interesse sobre dois ou mais bens, podendo, contudo, adquirir ou usufruir apenas de um deles, fala-se da existência de conflito subjetivo ou individual. Através da renúncia, sacrifício ou aceitação, se suas condições possibilitam relacionar-se apenas com um bem, acaba por escolher aquele que, dentro de sua escala de valores, atenda melhor às suas necessidades. Por outro lado, quando duas ou mais pessoas têm interesse sobre o mesmo bem verifica-se a existência de um conflito intersubjetivo ou interpessoal, ou meramente conflito de interesses, caracterizado pela unidade de objeto e pluralidade de sujeitos.
\end{abstract}

Por isso, todos os atos relacionados ao atendimento das necessidades da criança e do adolescente devem ter como critério a perspectiva dos seus melhores interesses. Essa perspectiva é orientadora das ações da família, da sociedade e do Estado, que nos processos de tomada de decisão, sempre, devem considerar quais as oportunidades e facilidades que melhor alcançam os interesses da infância. Conforme Wolkmer² ${ }^{24}$

Toda sociedade, buscando satisfazer as necessidades fundamentais e dirimir as pretensões crescentes, tenderá a fixar um núcleo de regras ou imperativos juridicamente institucionalizados. Assim sendo, uma das funções básicas do Direito é a arbitragem do jogo de forças e reivindicações em conflito, pois é no dialético impasse das vontades que teleologicamente o Direito realiza seu intento: a proteção de um interesse em face da postergação de outro interesse e o reconhecimento da legitimidade de dominação de um interesse sobre outro interesse.

Neste contexto, o interesse superior da criança é o critério estruturante de organização sistemática do direito, entre seus vários campos, mas também no interior do próprio Direito da Criança e do Adolescente, pois visa a orientar todas as ações voltadas à realização dos direitos fundamentais. Bruñol ${ }^{25}$ declara que: 
Desde o reconhecimento explícito de um catálogo de direito, são superadas as expressões programáticas do 'interesse superior da criança' e é possível afirmar que o interesse superior da criança é a plena satisfação de seus direitos. O conteúdo do princípio são os próprios direitos; interesse e direitos, neste caso, se identificam. Todo 'interesse superior' passar a estar mediado por referir-se estritamente a 'declarado direito'; por sua vez, somente o que é considerado direito por ser 'interesse superior'.

Intrinsecamente relacionado com o interesse superior da criança, está o princípio da prioridade absoluta. $\mathrm{O}$ art. 227, da Constituição Federal, e o art. 4ㅜ, do Estatuto da Criança e do Adolescente, atribuem como dever da família, da sociedade e do Estado a responsabilidade em assegurar os direitos fundamentais, estabelecendo que sua realização deve ser realizada com absoluta prioridade. $\mathrm{O}$ art. $4^{\circ}$, Parágrafo Único, do Estatuto da Criança e do Adolescente determina o alcance da garantia de absoluta prioridade:

A garantia de prioridade compreende: a) primazia de receber proteção e socorro em quaisquer circunstâncias; b) precedência de atendimento nos serviços públicos ou de relevância pública; c) preferência na formulação e na execução das políticas sociais públicas; d) destinação privilegiada de recursos públicos nas áreas relacionadas com a proteção à infância e à juventude.

Além de servir como critério interpretativo na solução de conflitos, o princípio da prioridade absoluta reforça verdadeira diretriz de ação para a efetivação dos direitos fundamentais, na medida em que estabelece a prioridade na realização das políticas sociais públicas e a destinação privilegiada dos recursos necessários à sua execução. Para que seja possível a efetiva realização dos direitos proclamados, as políticas públicas precisam alcançar um patamar diferenciado das práticas historicamente estabelecidas na tradição brasileira, por isso a importância do princípio, a ênfase nas políticas sociais básicas, pois esta é a determinação do Estatuto da Criança e do Adolescente em seu art. 87, I, que o incorpora como uma de suas linhas de ação.

Trata-se da tentativa de superação das práticas assistencialistas, meramente emergenciais e segmentadas, que excluíam a maior parte do universo das crianças e adolescentes da possibilidade de usufruir os serviços decorrentes das políticas sociais básicas definidas como o conjunto dos "[...] benefícios ou serviços de prestação pública dos quais podemos dizer: 'isto é direito de todos e dever do Estado', ou seja, as políticas sociais básicas dirigem-se ao universo mais amplo possível de destinatários, sendo, portanto, de prestação universal. ${ }^{26}$ Para Baratta ${ }^{27}$ :

O princípio central da estratégia dirigida a implementar uma proteção integral dos direitos da infância é o restabelecer a primazia das políticas sociais básicas, respeitando a proporção entre estas áreas e as outras políticas públicas previstas na Convenção. Isto significa, em primeiro lugar, que as políticas sociais básicas têm uma função primária e geral e que, com respeito a estas, todas as outras políticas devem ser subsidiárias e residuais; em segundo lugar, que a concepção dinâmica do princípio da igualdade impõe aos Estados membros da Convenção e à comunidade internacional, respectivamente, o respeito de um padrão mínimo de normas do 
Estado social e de uma regulação do desenvolvimento econômico que respeite os critérios do desenvolvimento humano e não seja contrário a eles.

O princípio da ênfase nas políticas sociais básicas visa a promover 0 reordenamento institucional, provendo um conjunto de serviços de efetivo atendimento às necessidades de crianças, adolescentes e suas próprias famílias por meio de políticas de promoção e defesa de direitos, bem como, de atendimento em todos os campos destinados à efetivação dos direitos fundamentais. Isso implica também no reconhecimento da assistência social como um campo específico de políticas públicas com caráter emancipatório, desvinculado dos tradicionais laços assistencialistas e clientelistas.

A universalização dos serviços públicos, através das políticas sociais básicas, impõe a implementação de verdadeiras redes de atendimento à população, pois:

Se o dever do Estado conduz à definição de políticas sociais básicas, o direito de todos leva à existência de direito público subjetivo, exercitável, portanto, contra o Poder Público. Assim, reconhece-se que o interesse tutelado pelo direito social tem força subordinante, isto é, subordina o Estado ao atendimento das necessidades humanas protegidas pela lei. ${ }^{28}$

Assim, a implementação das políticas públicas requer o respeito ao princípio da descentralização político-administrativa, pois estas políticas devem ser realizadas no lugar onde vivem as pessoas. O Estatuto da Criança e do Adolescente determina no art. 86 que: "a política de atendimento dos direitos da criança e do adolescente far-se-á através de um conjunto articulado de ações governamentais e não-governamentais, da União, dos estados, do Distrito Federal e dos municípios". Especificamente, em relação às políticas de assistência social, a própria Constituição Federal é clara e determina no art. 204: "I - descentralização político-administrativa cabendo a coordenação e as normas gerais à esfera federal e a coordenação e a execução dos respectivos programas às esferas estadual e municipal, bem como a entidades beneficentes e de assistência social".

A descentralização deve estar acompanhada de canais democráticos de participação popular, capazes de reivindicar a continuidade e permanência das ações neste campo.

A questão da continuidade das ações é algo que deve ser salientado, dado o fato que se convive muito com a dramática experiência de que, com a mudança dos governos, reformulam-se todos os programas, como se não mais fossem necessárias as propostas do governo anterior, o que revela imaturidade política, demonstrando que o poder gira em torno de personalidade mais preocupadas com o próprio status de dominador do que com o verdadeiro bem-estar de seus concidadãos. Tal situação ocorre, entre outras causas, nas sociedades cujas instituições ainda não estão solidamente constituídas. ${ }^{29}$

A descentralização tem o mérito da aproximação da política, bem como do direito da realidade social concreta, o que estimula novas relações 
democráticas e participativas, muitas vezes consideradas como núcleo essencial do processo de construção de políticas públicas. No entanto, esse papel:

[...] pode ser cumprido com êxito somente se a rede das relações democráticas de poder e de participação estão desenvolvidas de maneira suficiente na comunidade local. Por outro lado, a experiência mostrou que as necessidades das crianças e a percepção destas necessidades e direitos podem tornar-se um momento construtivo e evolutivo da cultura da democracia e da legalidade democrática na interior da comunidade local. ${ }^{30}$

O princípio da participação popular na construção das políticas públicas prevê ação articulada, entre sociedade civil e Estado, com a atuação dos Conselhos dos Direitos da Criança e do Adolescente, como órgãos paritários e controladores das ações em todos os níveis. Este princípio visa estabelecer formas de participação ativa e crítica na formulação das políticas públicas, garantindo instrumentos de fiscalização e controle, amparando as exigências da sociedade quanto à efetivação das políticas com qualidade e em quantidade adequadas. Para $S E M^{\beta 1}$ é indispensável a participação social nestes processos,

\begin{abstract}
A questão da discussão pública e participação social é, portanto, central para elaboração de políticas em uma estrutura democrática. 0 uso de prerrogativas democráticas - tanto as liberdades políticas como os direitos civis - é parte crucial do exercício da própria elaboração de políticas econômicas, em adição a outros papéis que essas prerrogativas possam ter. Em uma abordagem orientada para a liberdade, as liberdades participativas não podem deixar de ser centrais para a análise das políticas públicas.
\end{abstract}

A construção de um projeto emancipador que torne possível uma nova perspectiva de cultura política encerra em si a questão da participação. As ações da sociedade civil vêm ganhando corpo e legitimidade, principalmente nos últimos anos, em decorrência da conquista de novos espaços sociais e de uma postura crítica positiva em relação aos papéis que devem ser desempenhados pelo Estado.

A participação popular também se viu reforçada com o reenquadramento das políticas públicas no campo da administração do Poder Executivo. A tradicional doutrina menorista mantinha junto ao Poder Judiciário uma série de atribuições estranhas a esse poder, mas legitimada pelo histórico papel de repressão e controle social. O princípio da desjurisdicionalização veio para corrigir esta incongruência. O Senador Ronan Tito ${ }^{32}$, explica na justificativa do Projeto de Estatuto da Criança e do Adolescente:

Cabe destacar também, no perfil geral deste projeto de Estatuto, o esforço de desjurisdição da grande maioria dos casos hoje objeto de decisão dos magistrados. Alegarão alguns que o novo Estatuto 'retirar atribuições' dos senhores Juízes de Menores, hoje sobrecarregados de trabalho e desviados das verdadeiras finalidades da função judicante, uma vez que forçados a controlar e administrar a pobreza e as mazelas sociais dela resultantes. Contraditando frontalmente essa alegação, o Estatuto sobreleva, dignifica e resgata a função precípua do magistrado, que passará a ater-se nesta área ao exercício de uma 
das mais nobres e elevadas funções sociais, qual seja, sem dúvida alguma, a distribuição da justiça.

A desjurisdicionalização pretende definitivamente afastar do campo do Poder Judiciário a função assistencial, pois não é essa a razão da Justiça. Cabe ao Poder Público através do Poder Executivo prover os serviços necessários de atendimento à criança e ao adolescente. No entanto, o Poder Judiciário é chamado a assumir um novo papel mais comprometido com a efetivação dos direitos fundamentais quando estes não estiverem ao alcance necessário à sua concretização.

Isso não significa a absoluta individualização das responsabilidades com a efetivação dos direitos fundamentais da criança e do adolescente, mas a verdadeira ação compartilhada e complementar no sistema de garantias de direitos orientado pela integração operacional dos órgãos do poder público responsáveis pela aplicação do Direito da Criança e do Adolescente.

O princípio da despoliciação, que implica também na descriminalização, elevou a efetivação dos direitos da criança e do adolescente para um novo patamar, ou seja, àquele que reconhece a efetivação dos direitos por meio de políticas públicas de promoção, substituindo as práticas repressivas e de controle social, vigentes no menorismo. ${ }^{33}$

O Direito da Criança e do Adolescente tem a sua própria teleologia e axiologia, amparados pelo reconhecimento de princípios promocionais e intimamente ligados com o princípio da dignidade da pessoa humana e dos direitos humanos em seu contexto mais amplo. Por isso, sua interpretação requer o reconhecimento da criança e do adolescente em sua condição peculiar de pessoa em desenvolvimento tendo uma teleologia social, valorizando o bem comum, os direitos e garantias individuais e coletivos, como determina 0 art. 6ํㅡㄹ do Estatuto da Criança e do Adolescente.

Propugnamos, portanto, por uma interpretação conforme os direitos
fundamentais constitucionalmente garantidos (insculpidos nos valores
e princípios constitucionais), em que estes de fato conformem a
decisão de qualquer instância judicial, como respeito ao sistema
jurídico hierárquico-axiológico. Dar-se-á, dessa forma, passo
importante e imprescindível para a concretização dos direitos
fundamentais, inclusos os direitos sociais, estabelecendo-se amplas
possibilidades de o Judiciário converter-se em implementador desses
preceitos. ${ }^{34}$

O desafio está na construção de uma teoria da tradução que ampare significados comuns nas diferentes lutas entre os atores coletivos, que identifiquem possibilidades de diálogo sobre as opressões das quais são vítimas e resistem e nas aspirações e desejos daquilo que se pretende construir. ${ }^{35}$ Segundo Luz ${ }^{36}$,

Finalmente, se ainda é possível pensar com seriedade a validade da máxima para qual a 'humanidade só se propõe às tarefas que pode resolver', a questão da teoria crítica, no campo das práticas jurídicas, terá de enfrentar, a partir dos diálogos com as experiências já construídas, uma fundamentação de valores - o que o positivismo jurídico clássico sempre renegou - de forma que seja colocado no 
centro das atenções o tão antigo e permanente debate sobre justiça.

Uma reflexão sobre justiça no Direito da Criança e do Adolescente se faz necessária e implica no repensar das trajetórias culturais, jurídicas e sociais estabelecidas ao longo da história brasileira e o despertar "[...] para a construção de um pensamento crítico-interdisciplinar, marcado por uma racionalidade jurídica emancipadora e por uma ética da alteridade, expressão de novas práticas sociais participativas." ${ }^{37}$

Sabe-se que pouca efetividade será alcançada sem o compromisso firme com o princípio da tríplice responsabilidade compartilhada, segundo o qual a família, a sociedade e o Estado têm o dever de assegurar os direitos fundamentais da criança e do adolescente. Neste contexto, a articulação dos princípios do Direito da Criança e do Adolescente para sua aplicação na realidade concreta pode desempenhar um papel pedagógico, verdadeiramente provocador da cidadania, da democracia e das necessárias transformações sociais e políticas. Esse é o fundamento emancipatório da Teoria da Proteção Integral.

\section{CONSIDERAÇÕES FINAIS}

A teoria da proteção integral estabeleceu-se como pressuposto para a compreensão do Direito da Criança e do Adolescente no Brasil contemporâneo em razão de sua própria condição estruturante do novo ramo jurídico autônomo que se estabeleceu a partir de 1998. Para muito além de mudanças tão somente restritas no campo formal, o que se pode observar é uma ruptura paradigmática que produziu um campo de abertura sistêmica capaz de potencializar a concretização dos direitos fundamentais reconhecidos às crianças e adolescentes.

O Direito da Criança e do Adolescente surge no cenário brasileiro com o necessário reconhecimento de direitos fundamentais à população infantojuvenil atribuindo a estes direitos o status de prioridade absoluta. Para que uma declaração de tal magnitude e abrangência não ficasse tão somente no plano discursivo, o Estatuto da Criança e do Adolescente, como norma disciplinadora da teoria da proteção integral previu um reordenamento político e institucional que resultou na criação do sistema de garantias de direitos da criança e do adolescente.

Os princípios concretizantes e estruturantes da teoria da proteção integral, com a necessária interdisplinaridade, apontam para transformações profundas no campo das concepções, da linguagem e da própria produção da realidade social. É claro, que não se pode desconsiderar a magnitude das violências produzidas por sistema econômico excludente e socialmente injusto. Contudo, as garantias jurídicas oferecem possibilidades de, ao menos, resistir à avassaladora opressão que se estabelece cotidianamente.

As possibilidades emancipatórias contidas na teoria da proteção integral, ainda sufocadas por certo viés menorista de parte dos atores sociais, tendem à libertação na medida em que se eleva o nível de politização e ampliam-se os 
espaços de participação democrática. O reconhecimento da condição de sujeitos de direitos às crianças e aos adolescentes, bem como, o próprio crescimento nos níveis de controle a participação social nas políticas públicas apontam para possibilidades interessantes no sentido da realização das utopias desejadas há muito tempo.

\title{
THEORY OF THE INTEGRAL PROTECTION: ESTIMATED OF UNDERSTANDING OF THE CHILD AND ADOLESCENT RIGHT
}

\begin{abstract}
The article analyzes the theory of the integral protection and the Right of the Child and the Adolescent. It describes the principles of the theory of the integral protection, it analyzes the doctrine of the irregular situation and studies the legal beddings for concretion of the rights of the child and the adolescent in Brazil contemporary.
\end{abstract}

Keywords: Adolescent. Child. Protection. Rights. Theory.

\section{NOTAS}

Professor no Curso de Direito da Universidade do Extremo Sul Catarinense, Pesquisador do Núcleo de Estudos em Estado, Política e Direito (NUPED/UNESC), Pesquisador do Núcleo de Estudos Jurídicos e Sociais da Criança e do Adolescente (NEJUSCA/UFSC), Coordenador Executivo do Instituto Ócio Criativo, Fellow da Ashoka Empreendedores Sociais, Doutor em Direito (CPGD/UFSC), Mestre em Direito (CPGD/UFSC), Graduado em Direito (CCJ/UFSC).

1 KUHN, Thomas S. A estrutura das revoluções científicas. 3 ed. São Paulo: Perspectiva, 1994, p. 39.

2 BRASIL. Decreto n. 17.934-A, de 12 de outubro de 1927. Coleção de Leis do Brasil, Poder Executivo, Rio de Janeiro, v. 2, p. 476, c. 1, 31 dez. 1927.

3 BRASIL. Lei n. 6.697, de 10 de outubro de 1979. Diário Oficial da União, Brasília, DF, v. 1, p. 14945, 11 out. 1979.

4 BRASIL, Senado Federal, Subsecretaria de Edições Técnicas. Código de Menores: Lei no 6.697/79, comparações, anotações, histórico, por Ana Valderez A. N. de Alencar e Carlos Alberto de Souza Lopes. Brasília: Senado Federal, 1982, p. 85.

5 LEITE, Carla Carvalho. Da doutrina da situação irregular à doutrina da proteção integral: aspectos históricos e mudanças paradigmáticas. Juizado da Infância e da Juventude, Porto Alegre, n. 5, mar. 2005 , p. 14.

6 VERONESE, Josiane Rose Petry, OLIVEIRA, Luciene Cássia Policarpo, BARBOSA, Vivian Sandoval. Menoridade Civil: algumas reflexões sobre a teoria das incapacidades. Revista da Faculdade de Direito da UFSC, Florianópolis, n. 2, 1999, p. 140.

7 VERONESE, Josiane Rose Petry. Os Direitos da Criança e do Adolescente. São Paulo: Ltr, 1999, p. 33.

8 LIMA, Miguel M. Alves. O Direito da Criança e do Adolescente: fundamentos para uma abordagem principiológica. Tese (Doutorado em Direito) - Curso de Pós-Graduação em Direito, Universidade Federal de Santa Catarina, Florianópolis, 2001, p. 62.

9 RAMIDOFF, Mário Luiz. Direito da Criança e do Adolescente: por uma propedêutica jurídicoprotetiva transdiciplinar. Tese (Doutorado em Direito) - Curso de Pós-Graduação em Direito, Universidade Federal do Paraná, Curitiba, 2007, p. 21.

10 BRASIL. Constituição (1988). Constituição da República Federativa do Brasil de 05 de outubro de 
1988. Diário Oficial [da] União, Poder Legislativo, Brasília, n. 191-A, 05 de out. 1988.

11 COSTA, Marli M. M. da, HERMANY Ricardo. A concretização do princípio da dignidade humana na esfera local como fundamento do estado democrático de direito frente à pobreza, à exclusão social e à delinqüência juvenil. Revista do Direito, Santa Cruz do Sul, n. 26, jul./dez. 2006, p. 168.

12 RAMIDOFF, Mário Luiz. Op. Cit. p. 202.

13 VERONESE, Josiane Rose Petry, RODRIGUES, Walkíria Machado. A figura da criança e do adolescente no contexto social: de vítimas a autores de ato infracional. In: VERONESE, Josiane Rose Petry, SOUZA, Marli Palma, MIOTO, Regina Célia Tamaso (Orgs.). Infância e Adolescência, o conflito com a lei: algumas discussões. Florianópolis: Funjab, 2001, p. 35.

14 KUHN, Thomas S. Op. Cit. p. 26.

15 KUHN, Thomas S. Op. Cit. p. 116.

16 LIMA, Miguel M. Alves. Op. Cit. p. 80.

17 RAMIDOFF, Mário Luiz. Op. Cit. p. 83.

18 ROCHA, Eduardo Gonçalves, PEREIRA, Julyana Faria. Descentralização participativa e a doutrina da proteção integral da criança e do adolescente. Revista da UFG, v. 5, n. 2, dez., 2003. Disponível em: <http://www.proec.ufg.br/revista_ufg/infancia/P_descentraliza.html>. Acesso em: 03 mar. 2008.

19 BRUÑ̃L, Miguel Cillero. O interesse superior da criança no marco da Convenção Internacional sobre os Direitos da Criança. In: MÉNDEZ, Emilio García, BELOFF, Mary (Orgs.). Infância, Lei e Democracia na América Latina: Análise Crítica do Panorama Legislativo no Marco da Convenção Internacional sobre os Direitos da Criança 1990 - 1998. Trad. Eliete Ávila Wolff. Blumenau: Edifurb, 2001, v. 1, p. 101.

20 LIMA, Miguel M. Alves. Op. Cit. p. 169.

$21 \quad$ Idem, ibidem, p. 215.

22 VERONESE, Josiane Rose Petry. Humanismo e infância: a superação do paradigma da negação do sujeito. In: MEZZAROBA, Orides (Org.). Humanismo Latino e Estado no Brasil. Florianópolis: Fundação Boiteux, Treviso: Fondazione Cassamarca, 2003, p. 439.

23 PAULA, Paulo Afonso Garrido de. Educação, Direito e Cidadania. In: ABMP. Cadernos de Direito da Criança e do Adolescente. v. 1. São Paulo: Malheiros, 1995, p. 91.

24 WOLKMER, Antonio Carlos. Ideologia, Estado e Direito. 3. ed. São Paulo: RT, 2000, p. 171-172.

25 BRUÑOL, Miguel Cillero. Op. Cit. p. 102.

26 COSTA, Antônio Gomes da. O Estatuto da Criança e do Adolescente e o Trabalho Infantil: trajetória, situação atual e perspectivas. Brasília: OIT, São Paulo: LTr, 1994, p. 43.

27 BARATTA, Alessandro. Infância e Democracia. In: MÉNDEZ, Emilio García, BELOFF, Mary (Orgs.). Infância, Lei e Democracia na América Latina: Análise Crítica do Panorama Legislativo no Marco da Convenção Internacional sobre os Direitos da Criança 1990 - 1998. Trad. Eliete Ávila Wolff. Blumenau: Edifurb, 2001, v. 1, p. 49.

28 PAULA, Paulo Afonso Garrido de. Op. Cit. p. 94.

29 VERONESE, Josiane Rose Petry. Temas de Direito da Criança e do Adolescente. São Paulo: LTr, 1997, p. 52.

30 BARATTA, Alessandro. Op. Cit. p. 51.

31 SEN, Amartya, Desenvolvimento como liberdade. Trad. Lauro Teixeira Motta. São Paulo: Companhia das Letras, 2000, p. 134.

32 TITO, Ronan, AGUIAR, Nelson. A justificativa do Estatuto. In: PEREIRA, Tânia da Silva (Org.). Estatuto da Criança e do Adolescente: Lei 8.069/90: Estudos "Sócio-Jurídicos". Rio de Janeiro: Renovar, 1992, p. 40.

33 PEREIRA, Tânia da Silva. A Convenção e o Estatuto. In: ___ (Org.). Estatuto da Criança e do Adolescente: Lei 8.069/90: Estudos "Sócio-Jurídicos". Rio de Janeiro: Renovar, 1992, p. 83.

34 PARDO, David Wilson de Abreu. Interpretação Tópica e Sistemática da Constituição. In: DOBROWOLSKI, Sílvio (Org.). A Constituição no Mundo Globalizado. Florianópolis: Diploma Legal, 2000, p. 73.

35 SANTOS, Boaventura de Sousa. A crítica da razão indolente: contra o desperdício da experiência: Para um novo censo comum: a ciência, o direito e a política na transição paradigmática. São Paulo: Cortez, 2000, p. 27.

36 LUZ, Vladimir de Carvalho Luz. Assessoria Jurídica Popular no Brasil. Rio de Janeiro: Lúmen Juris, 2008, p. 218.

37 WOLKMER, Antônio Carlos. História do Direito no Brasil. 2. ed. Rio de Janeiro: Forense, 2000, p. 142. 


\section{REFERÊNCIAS}

BARATTA, Alessandro. Infância e Democracia. In: MÉNDEZ, Emilio García, BELOFF, Mary (Orgs.). Infância, Lei e Democracia na América Latina: Análise Crítica do Panorama Legislativo no Marco da Convenção Internacional sobre os Direitos da Criança 1990 - 1998. Trad. Eliete Ávila Wolff. Blumenau: Edifurb, 2001.

BRASIL. Constituição (1988). Constituição da República Federativa do Brasil de 05 de outubro de 1988. Diário Oficial [da] União, Poder Legislativo, Brasília, n. $191-A, 05$ de out. 1988.

Decreto n. 17.934-A, de 12 de outubro de 1927. Coleção de Leis do Brasil, Poder Executivo, Rio de Janeiro, v. 2, p. 476, c. 1, 31 dez. 1927.

. Lei n. 6.697, de 10 de outubro de 1979. Diário Oficial da União, Brasília, DF, v. 1, p. 14945, 11 out. 1979.

Senado Federal, Subsecretaria de Edições Técnicas. Código de Menores: Lei no 6.697/79, comparações, anotações, histórico, por Ana Valderez A. N. de Alencar e Carlos Alberto de Souza Lopes. Brasília: Senado Federal, 1982.

BRUÑOL, Miguel Cillero. O interesse superior da criança no marco da Convenção Internacional sobre os Direitos da Criança. In: MÉNDEZ, Emilio García, BELOFF, Mary (Orgs.). Infância, Lei e Democracia na América Latina: Análise Crítica do Panorama Legislativo no Marco da Convenção Internacional sobre os Direitos da Criança 1990 - 1998. Trad. Eliete Ávila Wolff. Blumenau: Edifurb, 2001.

COSTA, Antônio Gomes da. O Estatuto da Criança e do Adolescente e o Trabalho Infantil: trajetória, situação atual e perspectivas. Brasília: OIT, São Paulo: LTr, 1994.

COSTA, Marli M. M. da, HERMANY Ricardo. A concretização do princípio da dignidade humana na esfera local como fundamento do estado democrático de direito frente à pobreza, à exclusão social e à delinqüência juvenil. Revista do Direito, Santa Cruz do Sul, n. 26, p. 165-187, jul./dez. 2006.

KUHN, Thomas S. A estrutura das revoluções científicas. 3 ed. São Paulo: Perspectiva, 1994.

LEITE, Carla Carvalho. Da doutrina da situação irregular à doutrina da proteção integral: aspectos históricos e mudanças paradigmáticas. Juizado da Infância e da Juventude, Porto Alegre, n. 5, p. 9-24, mar. 2005.

LIMA, Miguel M. Alves. O Direito da Criança e do Adolescente: fundamentos para uma abordagem principiológica. Tese (Doutorado em Direito) - Curso de Pós-Graduação em Direito, Universidade Federal de Santa Catarina, Florianópolis, 2001.

LUZ, Vladimir de Carvalho Luz. Assessoria Jurídica Popular no Brasil. Rio de Janeiro: Lúmen Juris, 2008. 
PARDO, David Wilson de Abreu. Interpretação Tópica e Sistemática da Constituição. In: DOBROWOLSKI, Sílvio (Org.). A Constituição no Mundo Globalizado. Florianópolis: Diploma Legal, 2000.

PAULA, Paulo Afonso Garrido de. Educação, Direito e Cidadania. In: ABMP. Cadernos de Direito da Criança e do Adolescente. v. 1. São Paulo: Malheiros, 1995.

PEREIRA, Tânia da Silva. A Convenção e o Estatuto. In: (Org.). Estatuto da Criança e do Adolescente: Lei 8.069/90: Estudos "Sócio-Jurídicos". Rio de Janeiro: Renovar, 1992.

RAMIDOFF, Mário Luiz. Direito da Criança e do Adolescente: por uma propedêutica jurídico-protetiva transdiciplinar. Tese (Doutorado em Direito) Curso de Pós-Graduação em Direito, Universidade Federal do Paraná, Curitiba, 2007.

ROCHA, Eduardo Gonçalves, PEREIRA, Julyana Faria. Descentralização participativa e a doutrina da proteção integral da criança e do adolescente. Revista da UFG, v. 5, n. 2, dez., 2003. Disponível em: $<$ http://www.proec.ufg.br/revista ufg/infancia/P descentraliza.html>. Acesso em: 03 mar. 2008.

SANTOS, Boaventura de Sousa. A crítica da razão indolente: contra 0 desperdício da experiência: Para um novo censo comum: a ciência, o direito e a política na transição paradigmática. São Paulo: Cortez, 2000.

SEN, Amartya, Desenvolvimento como liberdade. Trad. Lauro Teixeira Motta. São Paulo: Companhia das Letras, 2000.

TITO, Ronan, AGUIAR, Nelson. A justificativa do Estatuto. In: PEREIRA, Tânia da Silva (Org.). Estatuto da Criança e do Adolescente: Lei 8.069/90: Estudos "Sócio-Jurídicos". Rio de Janeiro: Renovar, 1992.

VERONESE, Josiane Rose Petry. Humanismo e infância: a superação do paradigma da negação do sujeito. In: MEZZAROBA, Orides (Org.). Humanismo Latino e Estado no Brasil. Florianópolis: Fundação Boiteux, Treviso: Fondazione Cassamarca, 2003, p. 421-452.

. Os Direitos da Criança e do Adolescente. São Paulo: Ltr, 1999.

Temas de Direito da Criança e do Adolescente. São Paulo: LTr, 1997.

VERONESE, Josiane Rose Petry, OLIVEIRA, Luciene Cássia Policarpo, BARBOSA, Vivian Sandoval. Menoridade Civil: algumas reflexões sobre a teoria das incapacidades. Revista da Faculdade de Direito da UFSC, Florianópolis, n. 2, p. 123-141, 1999.

VERONESE, Josiane Rose Petry, RODRIGUES, Walkíria Machado. A figura da criança e do adolescente no contexto social: de vítimas a autores de ato infracional. In: VERONESE, Josiane Rose Petry, SOUZA, Marli Palma, MIOTO, Regina Célia Tamaso (Orgs.). Infância e Adolescência, o conflito com a lei: algumas discussões. Florianópolis: Funjab, 2001.

WOLKMER, Antônio Carlos. História do Direito no Brasil. 2. ed. Rio de Janeiro: Forense, 2000. . Ideologia, Estado e Direito. 3. ed. São Paulo: RT, 2000. 
Recebido para publicação 16/05/2008

Aceito para publicação 15/12/2008 